\title{
Asymmetries in regional development: Does TFP or capital accumulation matter for spatial inequalities?
}

\author{
Hasan Engin Duran \\ Izmir Institute of Technology, City and Regional Planning Department, Turkey
}

\section{A R T I C L E I N F O}

\section{JEL classification:}

R11

R12

R15

Keywords:

Regional inequality

TFP

Factor endowments

VAR variance decomposition

\begin{abstract}
A B S T R A C T
In the literature on regional inequalities, commonly adopted Neo-Classical theoretical framework $\left(Y=A K^{\alpha}(h L)^{1-\alpha}\right)$ implies that disparities may arise for two reasons, either due to differences in factor endowments or TFP differentials. In the current study, we address the following rarely examined questions: i. Do regional income inequalities arise due to TFP or factor endowment disparities across regions? ii. What's their relative contribution to the level of and change in regional inequality? Our dataset covers the period 2004-2014 and 81 Turkish provinces. We use mathematical decompositions, Panel unit root, panel VAR and generalized impulse-response analyses. Results are summarized in two groups. First, the main contributor to income inequality is the disparity in regional factor endowments, whereas TFP differentials are relatively less influential. Second, the main source of decline in disparities seems to be the narrowing of TFP differences.
\end{abstract}

\section{Introduction}

In the literature on regional inequalities, the vast majority of scholars rely on Neo-Classical foundation by assuming the diminishing marginal returns of capital accumulation (Solow, 1956; Swan, 1956). This implies a monotone saddle path through which each region tends to converge to the same steady state (Duran, 2014, 2015).

Most empirical studies in this field analyze the evolution of regional inequalities over time. In general, there have been quite mixed results on regional convergence/divergence (for studies on US regions or states see Barro \& Sala-i-Martin, 1992; Rey \& Montouri, 1999; Fan \& Casetti, 1994 for European regions, see Ertur, Le Gallo, \& Baumont, 2006; Lopez-Bazo, Vaya, Mora, \& Surinach, 1999; Armstrong, 1995).

The decline (or rise) in regional inequalities has very rarely been examined in terms of the mechanical causes.

In the Neo-Classical theoretical framework, commonly adopted production function $\left(Y=A K^{\alpha}(h L)^{1-\alpha}\right)$ implies that income disparities across regions may arise for two reasons: either due to disparities in factor endowments (such as capital, labor, human capital) or TFP (Total factor Productivity) differentials.

Distinguishing the relative importance of the two components is politically crucial. On the one hand, if regional disparities exist mainly due to disparities in factor endowments, then it will be sufficient for central governments to stimulate the investment processes in backward regions by directing funds and resources to these places. On the other hand, if income inequalities arise mostly due to productivity differentials, greater support is needed for lagging regions such as promotion of R\&D investments, techno parks, innovative activities, etc.

\footnotetext{
* Corresponding author. IYTE Gulbahce Kampüsü Mimarlık Fakültesi E-Blok, 35430, Urla, Izmir, Turkey.

E-mail address: enginduran@iyte.edu.tr.
} 
In the current study, we intend to analyze this issue in deep and try to answer the following questions:

i Do regional income inequalities arise due to TFP or factor endowment disparities?

ii What's their relative percentage contribution to the level of and change in inequality?

The above questions have been considered by few studies. One exceptional study is implemented by Beugelsdijk, Mariko and Milionis (2018) who analyzed this issue for 257 European NUTS-2 regions in 2007. The study found that only $20 \%$ of the inequalities are attributed to differences in factor endowments, whereas about $80 \%$ are due to TFP disparities. Two other studies which focused on the cross-country samples. Caselli (2005) identified the contribution of factor endowment disparities to income inequality across European economies as $25 \%$, and Hsieh and Pete Klenow (2010) found a similar ratio of about $30-50 \%$ at the global level, across 52 countries for the year 1996.

In the current study, we propose to extend the literature in several directions. First, so far the existing studies have analyzed this issue in a cross-sectional (fixed time) setting and by adopting a static approach. Most studies analyzed the sources of regional inequalities while leaving the sources of change in inequalities unexplored. We employ both a static and dynamic approach by analyzing the contribution of factors to the level and change in disparities.

As a second contribution, to our knowledge, this study represents one of the first studies in this field in Turkey. So far, regional TFP scores have not been computed, and the relative importance of both factors have not been analyzed with respect to their contribution to the emergence of regional inequalities.

Turkish literature has focused rather on income inequalities and convergence across provinces/regions. One common finding is the existence of regional disparities in development. The observed pattern is argued to be mostly due to the inadequacy of physical and human capital stocks, and disparities in new firm formation, regional market potential, entrepreneurship and infrastructure in the backward regions. (Karahasan, 2015a; Karahasan, Dogruel \& Dogruel, 2016). Moreover, liberal policies following the 1980 economic program (a milestone in Turkish economy towards liberalization) have been argued to favor already developed areas, widening the development gap (Gezici \& Hewings, 2007).

In terms of studies on convergence, there are two groups of results depending on the period of analysis. The first group represents rather older studies focusing on the period between 1975 and 2001. They often report evidence of rising income inequalities (see for instance, Kirdar and Saracoglu, 2008 (period of analysis: 1975-2000), Gezici and Hewings, 2007 (Period of Analysis: 1980-1997), Elveren, 2010 (Period of Analysis: 1980-2001)). On the other hand, there is a newer class of studies pointing to decreasing inequalities. These studies generally analyze the period after 2002. (see for instance, Gömleksiz, Şahbaz and Mercan, 2017 (period of analysis: 2004-2014), Oktay and Gozgor, 2013 (period of analysis: 2002-2008), Karahasan, 2015b (period of analysis: 2003-2008).

In this study, our dataset covers the period 2004-2014 and 81 Turkish provinces (NUTS-3 level regions). As for the methodology, we first, construct our variables. Initially, per worker real GDP variable is calculated for each province. Then, we calculate a Mincerian piecewise linear and parametrized human capital stock for each province by drawing on the methodology used in Hall and Jones (1999), Caselli (2005) and Beugelsdijk, Mariko and Milionis (2018). Provincial physical capital stocks are approximated by using per worker commercial electricity consumption data as there is no available capital formation and investment data at the regional level. Then, share of labor income and TFP scores for each province is calculated by using the same methodology as in Bryne, Fazio and Piacentino (2009). Finally, relative contribution of factor endowments and TFP differences to regional inequality are analyzed with the help of simple mathematical variance decompositions, Panel Unit Root and Panel VAR Generalized Impulse-Response Analyses.

The remaining parts of the paper is as follows; In section 2, we explain the data and measurement issues in detail. In section 3, we pursue our empirical analysis by first explaining the adopted methods and then presenting the obtained results. Finally, we conclude our study in the last section.

\section{Data and measurement}

In this study, we use the following Cobb-Douglas production function as standard in empirical analyses (Durlauf, Kourtellos and Tan, 2008);

$$
Y=A K^{\alpha}(L h)^{1-\alpha}
$$

where Y represents income, $\mathrm{K}$ represents capital, $\mathrm{L}$ denotes labor, $\mathrm{h}$ is human capital and $\alpha$ is the share of capital in total production. In per worker terms, the function becomes,

Table 1

Definition of variables.

\begin{tabular}{llll}
\hline Variable Name & Definition/Calculation & Period & Data Source \\
\hline y & Per worker real GDP & 2004-2014 & TURKSTAT \\
k & Per worker physical capital stock approximated by per worker commercial electricity consumption in provinces & 2004-2014 & TURKSTAT \\
h & Human capital stock in provinces approximated using average years of schooling data and Mincerian function & 2004-2014 & TURKSTAT \\
\hline
\end{tabular}

Note: All variables are used in a relative sense, assuming average province $=100$. 


$$
y=A k^{\alpha} h^{1-\alpha}
$$

Our initial task is to construct the variables $(y, k, h)$., the definition of which are summarized below in Table 1 . All regional data are collected from Turkish Statistical Institute's regional database (tuik: www.tuik.gov.tr).

\subsection{Calculation of $y, k, h$}

To start with $y$, we first obtain nominal total provincial GDP values. Then, total GDP values are divided by number of employees in provinces. However, employment data is not directly available for provinces. Therefore, we use employment rates for $2008-2013$ period. Then, we extrapolate backward the existing trend of employment rates in order to estimate the number of employee values for 2004-2007 by using straight line (arithmetic) method. Following this, we deflate the per worker GDP series by using NUTS-2 level regional consumer price indexes (on the basis of 2003 year). Finally, per worker real GDP values are used in the analysis.

Second, we calculate $k$ that represents per worker physical capital stocks in provinces. Since there is no available provincial data on gross capital formation (or investment flows), we opt using a proxy. Industrial electricity consumption is known as a successful proxy for physical capital stock in the literature (Burnside, Eichenbaum, \& Rebelo, 1996; Comin \& Gertler, 2006; Taylor, 1967). However, we argue that it has an important shortcoming; all regions do not have a unique share of industry in total production. Therefore, we prefer a proxy that signals broader consumption of electricity that should cover almost all sectors. Thus, we choose per worker commercial electricity consumption data in all sectors. ${ }^{1}$

In order to verify the robustness of the proxy, we chart in Fig. 1 the evolution of national commercial electricity consumption (in $\mathrm{MwH}$ ) and national physical capital stock values (obtained from Penn World Tables which is calculated by using a Perpetual Inventory Method (Feenstra, Robert Inklaar, \& Timmer, 2015)). Both the levels and first differences of two variables are presented.

As observed clearly, the two variables are quite well associated (as also found in Bosworth, 1979). Their evolution is consistently synchronous although electricity data seems to move more cyclically. This might be due to a rapid contraction of electricity usage in 2008-2009 Global financial crisis. The Pearson correlation coefficient between the two variables (in the first differenced form) is found as 0.84 (with high statistical significance; p-value: 0.002) which represents a high level of association. The correlation coefficient is even higher, once we calculate correlation coefficient using levels instead of first differences (coefficient:0.99, p-value: 0.000). Hence, we find it robust and safe to use the proxy in the remaining economic analysis.

Another variable used in the analysis is the stock of human capital. In order to calculate it, we first obtain data on percentages of population categorized with respect to graduation level (such as (\%) of population graduated only from primary school (it lasts 5 years), from 3 year lasting secondary school, from 3 year lasting high school, from a bachelor program (generally 4 years, however if it is a vocational training program, it lasts 2 years), from a master program ( 2 years) and from a PhD program (4 years). By using this data, we calculate average years of schooling for each province by applying the following formula:

$$
\text { ays }_{i, t}=\text { Primary }_{i, t} x 5+\text { Secondary }_{i, t} \times 8+\text { Highschool }_{i, t} \times 11+\text { Bachelor }_{i, t} \times 14.85+\text { Master }_{i, t} x 16.85+\text { Phd }_{i, t} \times 21.85
$$

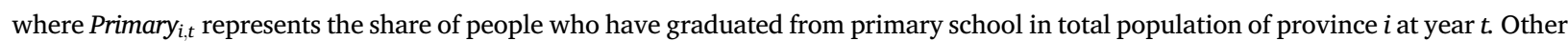
education levels are calculated in a similar way. ${ }^{2}$

Calculated average years of schooling data is available only for the 2008-2014 period. We apply a Mincerian piecewise linear and parametrized function to approximate the stocks of human capital (formula (4)'s parameters are adopted from the following studies; Beugelsdijk, Mariko \& Milionis, 2018; Mincer, 1984; Caselli, 2005; Hall \& Jones, 1999).

Specifically,

$$
\varnothing\left(\text { ays }_{i, t}\right)=\left\{\begin{array}{cc}
0.134 \times \text { ays } & \text { if ays }<4 \\
0.134 \times 4+0.101 \times(\text { ays }-4) & \text { if } 4 \leq \text { ays } \leq 8 \\
0.134 \times 4+0.101 \times 4+0.068 \times(\text { ays }-8) & \text { if ays }>8
\end{array}\right\}
$$

Then $h_{i, t}=e^{\varnothing\left(a y s_{i, t}\right)}$ represents the human capital stock. ${ }^{3}$

Once, we apply the function above and calculate $h_{i, t}$ for 2008-2014 period, then, we replace the remaining years values (for 2004-2007) by extrapolating its current trend backwards by using a geometric change method. Finally, we obtain human capital stock values for each province.

\subsection{Calculation of TFP (A)}

In the literature on regional TFP calculation, various techniques have been applied. There are 2 main methods. The first one is the regression technique. In this method, TFP scores are computed from the region specific constants (fixed effects) of the estimated regression equation of linearized production function (De La Fuente, 2002; Dettori, Marrocu, \& Paci, 2012). However, since our time

\footnotetext{
${ }^{1}$ With the only exception of electricity consumed in agricultural water usage as there is no available data for each province.

${ }^{2}$ Conventional bachelor degree lasts 4 years where vocational training programs lasts 2 years. About $2 / 3$ of university students graduate from conventional bachelor programs. So weighted average of duration of university study is calculated as 3.85 years.

3 equation (4) is adapted from Beugelsdijk, Mariko and Milionis (2018).
} 


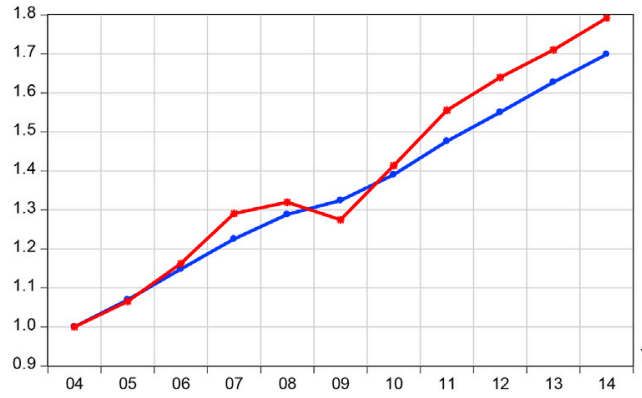

2004=1 Assumed

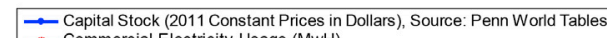
- Capital Stock (2011 Constant Prices in Dollars), Source: Penn World Tables
- Commercial Electricity Usage (MWH)

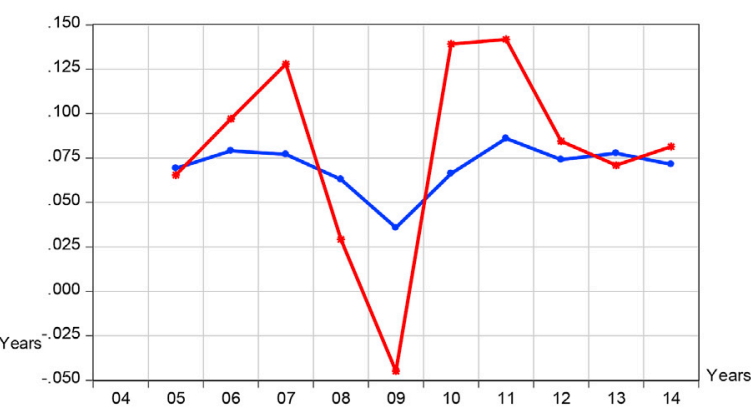
- First Differenced Capital Stock, Penn World Tables
$\square$ First Differenced Electricity Consumption $(\mathrm{MwH})$

Fig. 1. National Capital Stock, comparison of methods.

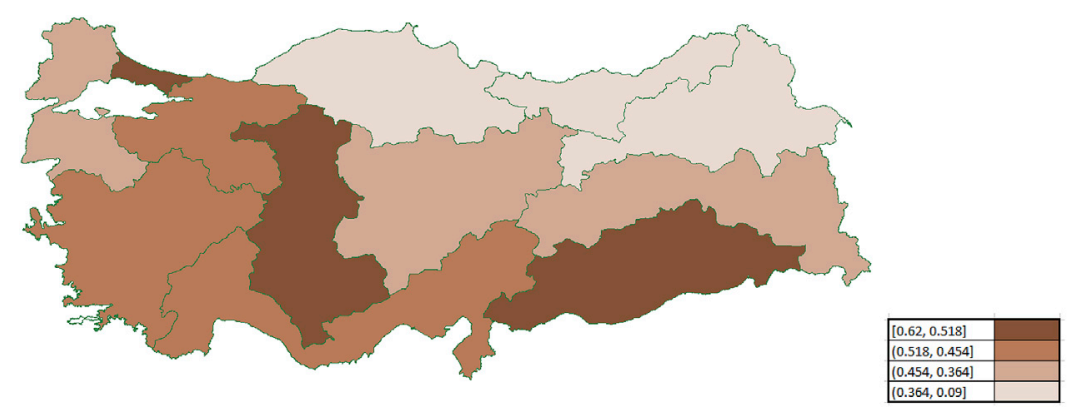

Fig. 2. Geographical Distribution of capital share $(\alpha)$.

span is short and due to the possibility of estimation error and bias, we prefer not to use this method. The second method, the one which we adopt, calculates directly the TFP scores from Cobb-Douglas production function (as in Beugelsdijk, Mariko \& Milionis, 2018; Bryne, Fazio \& Piacentino, 2009). So, TFP is represented by,

$$
A=\frac{y}{k^{\alpha} h^{1-\alpha}}
$$

In the formula, one needs to calculate/assume a value for $\alpha$ (share of capital in production process). In the standard macroeconomics literature, it is widely assumed as $\alpha=1 / 3 \cong 0.34$ (Brock \& German-Soto, 2013). However, presumption of cross regional constant $\alpha$ seems implausible as it varies significantly from a region to another. Hence, we prefer calculating a region specific $\alpha$ by using a method similar to in Bryne, Fazio and Piacentino (2009):

$$
1-\alpha=\frac{w L}{G V A} \text { or } \alpha=1-\frac{w L}{G V A}
$$

1- $\alpha$ term denotes the share of labor income in total economy. In detail, $w$ represents average of gross annual wages. $\mathrm{L}$ represents the total number of employees. GVA represents the GDP, net of subsidies and taxes. However, the data on $w$ is available only in 2008 and 2012 years and for 12 Nuts-1 regions. Therefore, we use average values of 2008 and 2012 . We assume that all provinces in the same (NUTS-1) region has an equal $\alpha$ value.

$\alpha$ value for aggregate Turkish economy is calculated by various researchers, but never at the regional level. The visualization of the regional $\alpha$ values are presented in a map below (Fig. 2) which has the average of $\alpha=0.4$ which is quite consistent with the literature.

At a glance, substantial variation across regions is observed (ranging from 0.09 to 0.62). While Northwestern, Middle Anatolian and Southeastern regions are more capital oriented, East and Northeastern economies are more labor intensive. This seems plausible as the Western part is more industrialized.

For the sake of robustness, we use both the cross-regional varying and constant $\alpha$ values in our analyses. Accordingly, we calculate the TFP scores for each province and period 2004-2014. From here onwards, A1 denotes TFP levels calculated using a cross-regional varying $\alpha$ where as A2 represents the TFP scores assuming constant $\alpha=0.34$. 


\section{Empirical analysis}

\subsection{Descriptive analysis}

A primary step in our analysis is to document the extent and the evolution of regional inequalities. We start with our target variable (y). We depict the geographical distribution of the variable in maps (Fig. 3) for the initial and end year (assuming the average province has a value of 100) and the evolution of its coefficient of variation (CoV) over the last decade in Fig. 4.

Looking at the maps, for the initial year, a West and Northeast income dualism is observed. The provinces that have highest income are the ones in Marmara region, Aegean coastal provinces and the ones surrounding Ankara, whereas the ones with least income is placed in Black Sea and Eastern part of the country. On average the most developed province has almost 6 times higher per worker income than the least developed one, which points to a large extend of inequalities.

However, through time, softening of the disparities and homogenization of income is observed. Yet, the visual inspection of Fig. 4 provides a clear tendency of inequalities to decline as the level of $\mathrm{CoV}$ falls from 0.43 to 0.32 . Consistently, the income convergence trend is verified also by Gömleksiz, Sahbaz, and Mercan (2017) who used per capita values instead of per worker data.

With respect to the other variables, their evolution of coefficient of variations are summarized in Table 2 from which some interesting features appear to emerge. For instance, highest disparities exist in capital stocks per worker (Cov: 1.04 initially) followed by disparities in income (Cov: 0.43), in TFP (Cov: 0.38 or 0.31) and human capital (Cov: 0.12). Hence, one may argue that largest share of inequalities might be mainly due to disparities in capital accumulation. However, this argumentation needs to be formally verified by mathematical and statistical decompositions.

Another important observation is that, in all variables, cross provincial disparities tend to decline. The sharpest decline, however, is seen in TFP disparities followed by human and physical capital. Hence, currently observed convergence trend might mainly be driven by the decrease in TFP differences, which is again to be verified by empirical analysis.

The geographical distribution of physical and human capital stocks is visualized in Fig. 5. It seems that North Western provinces have the highest value. The greatest imbalances are seen in the distribution of physical capital stocks, whereas human capital is relatively more evenly distributed. In both variables, a diffusion to the backward regions over the years is observed.

With regard to the calculated TFP scores, A1 and A2 variables are visualized in Fig. 6 Important notice is that the three big cities (Istanbul, Ankara, Izmir), Aegean coastal provinces, Ankara's surrounding provinces, some Middle Anatolian cities have the highest values whereas Northeastern provinces has the least productivity. In the end year, TFP pattern seems to be homogenized, scores are relatively equalized as standard deviation and Maximum/Minimum ratios fall.

The empirical examination of the relative contribution of variables to regional disparities is pursued in the next section.

\subsection{Sources of inequality level}

Cross regional variance of income is hardly decomposable into variables (k,h,A) as functional form of Cobb-Douglas does not allow for. One possible solution is provided by Caselli (2005). The decomposition takes the following form:

$$
\operatorname{var}\left(\log y_{i, t}\right)=\operatorname{var}\left(\log y f_{i, t}\right)+\operatorname{var}\left(\log A_{i, t}\right)+2 x \operatorname{cov}\left(\log A_{i, t}, \log y f_{i, t}\right)
$$

Where $y f_{i, t}=k_{i, t}{ }^{\alpha} h_{i, t}{ }^{1-\alpha}$ represents the aggregate input, in other words the output process implemented only through the help of production factors. As observed above, variance of income depends on the variance of aggregate input, TFP differences and the covariance between factor endowments and TFP. The decomposition results are presented in Table 3.
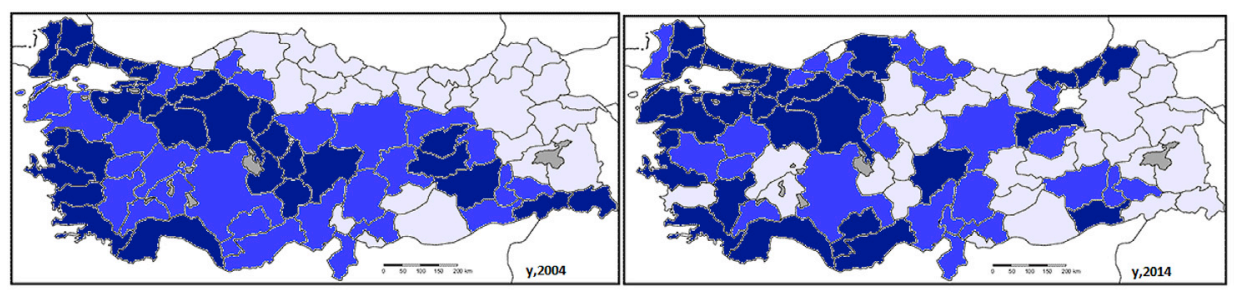

\begin{tabular}{|l|r|}
\hline Max & 226,84 \\
\hline Min & 38,56 \\
\hline SD & 42,93 \\
\hline
\end{tabular}
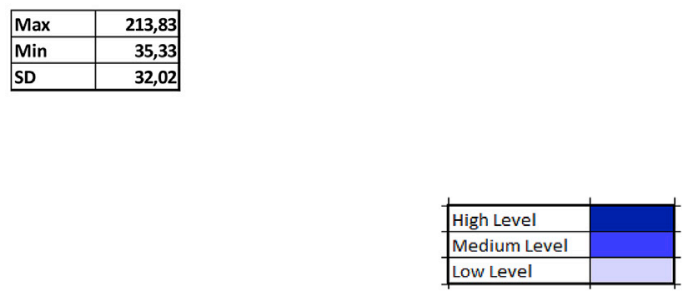

Fig. 3. Geographical Distribution of per worker income (y), average province $=100$. 


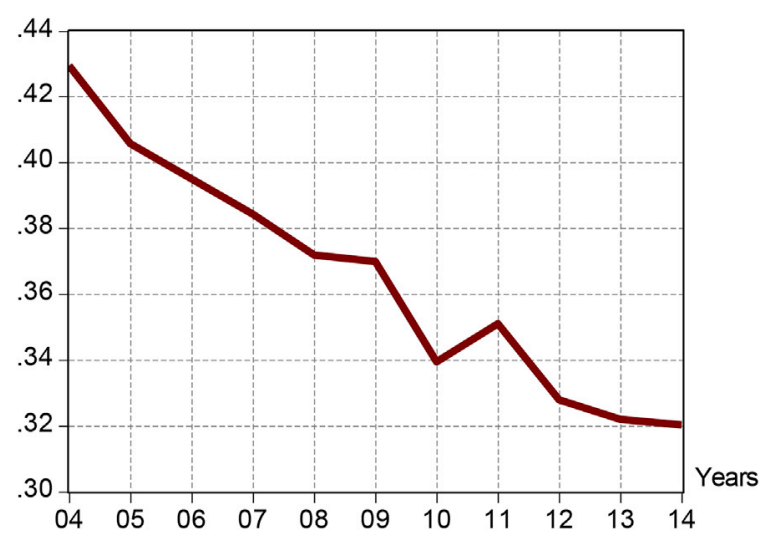

Fig. 4. Coefficient of Variation of Variables of Interest, y.

Table 2

Coefficient of Variation of all variables.

\begin{tabular}{llllll}
\hline Years & $\mathrm{y}$ & $\mathrm{h}$ & $\mathrm{k}$ & $\mathrm{A} 1$ & $\mathrm{~A} 2$ \\
\hline 2004 & 0,43 & 0,12 & 1,04 & 0,38 & 0,36 \\
2005 & 0,41 & 0,12 & 0,95 & 0,33 & 0,31 \\
2006 & 0,39 & 0,11 & 0,91 & 0,32 & 0,29 \\
2007 & 0,38 & 0,11 & 0,90 & 0,30 & 0,29 \\
2008 & 0,11 & 0,84 & 0,27 \\
2009 & 0,37 & 0,11 & 0,87 & 0,29 & 0,29 \\
2010 & 0,34 & 0,10 & 0,87 & 0,29 & 0,21 \\
2011 & 0,35 & 0,11 & 0,88 & 0,28 \\
2012 & 0,33 & 0,86 & 0,23 \\
2013 & 0,32 & 0,09 & 0,84 & 0,29 \\
2014 & 0,32 & 0,09 & 0,81 & 0,22 \\
\hline
\end{tabular}

We understand that contributions of both factor endowments and TFP differences are very important. However, the relationship between capital accumulation and TFP is negative that help reduce the income disparity. This may be possible if there are non-utilized capital (such as unused roads, infrastructure, factories) in developed areas (Scott, Dwyer \& Tamura, 2006).

The biggest problem with the decomposition above is that covariance term is not ignorable and hampers observing the pure contributions of $A$ and $y f$. Therefore, we come up with the following solution that allocate the non-zero covariance term equally to $\operatorname{var}\left(\log y f_{i, t}\right)$ and $\operatorname{var}\left(\log y f_{i, t}\right)$ :

$$
C_{i, t}=\frac{\operatorname{var}\left(\log y f_{i, t}\right)}{\operatorname{var}\left(\log y f_{i, t}\right)+\operatorname{var}\left(\log A_{i, t}\right)}
$$

Thus, $C_{i, t}$ represents a reduced form decomposition, the relative percentage contribution of factor endowment differences to overall income inequalities.

An interesting feature appears in Table 4 . On average about $55-65 \%$ of the observed income disparities is attributed to cross provincial differences in factor endowments whereas about 35-45\% proportion is due to TFP differentials. This finding is consistent regardless of whether region specific or constant share of capital is adopted in TFP calculation. Hence, one may argue that factor endowments is slightly a more severe cause of the observed inequality levels.

However, the results are in contrast to the findings in the literature. Beugelsdijk, Mariko and Milionis (2018) find the contribution of factor endowments much lower, such as $20-25 \%$ across European Nuts-2 regions, $24-32 \%$ across 21 EU countries, $22-29 \%$ across 38 British regions, 26-44\% across French regions, 11-15\% across German regions, 15-24\% across Italian regions and 30-53\% across Spanish regions. The difference between our results and findings in the literature may arise from the fact that the analyzed places are mostly the developed European regions which are likely to be more close to the end of capital accumulation process. Hence, it is logical that TFP differences contribute more to the inequality level, as there is relatively less disparity in factor endowments. In Turkish case, however, the capital accumulation is an ongoing process as it is a developing country. Hence, one may expect much greater disparities in capital accumulation and, therefore, more contribution to regional inequalities.

\subsection{Sources of decline in inequalities}

As anticipated before, declining regional inequalities is observed for Turkey. In current part, we start with examining formally the sources behind this decline. However, firstly we need to understand the technical time series property of our variables. To do so, we 

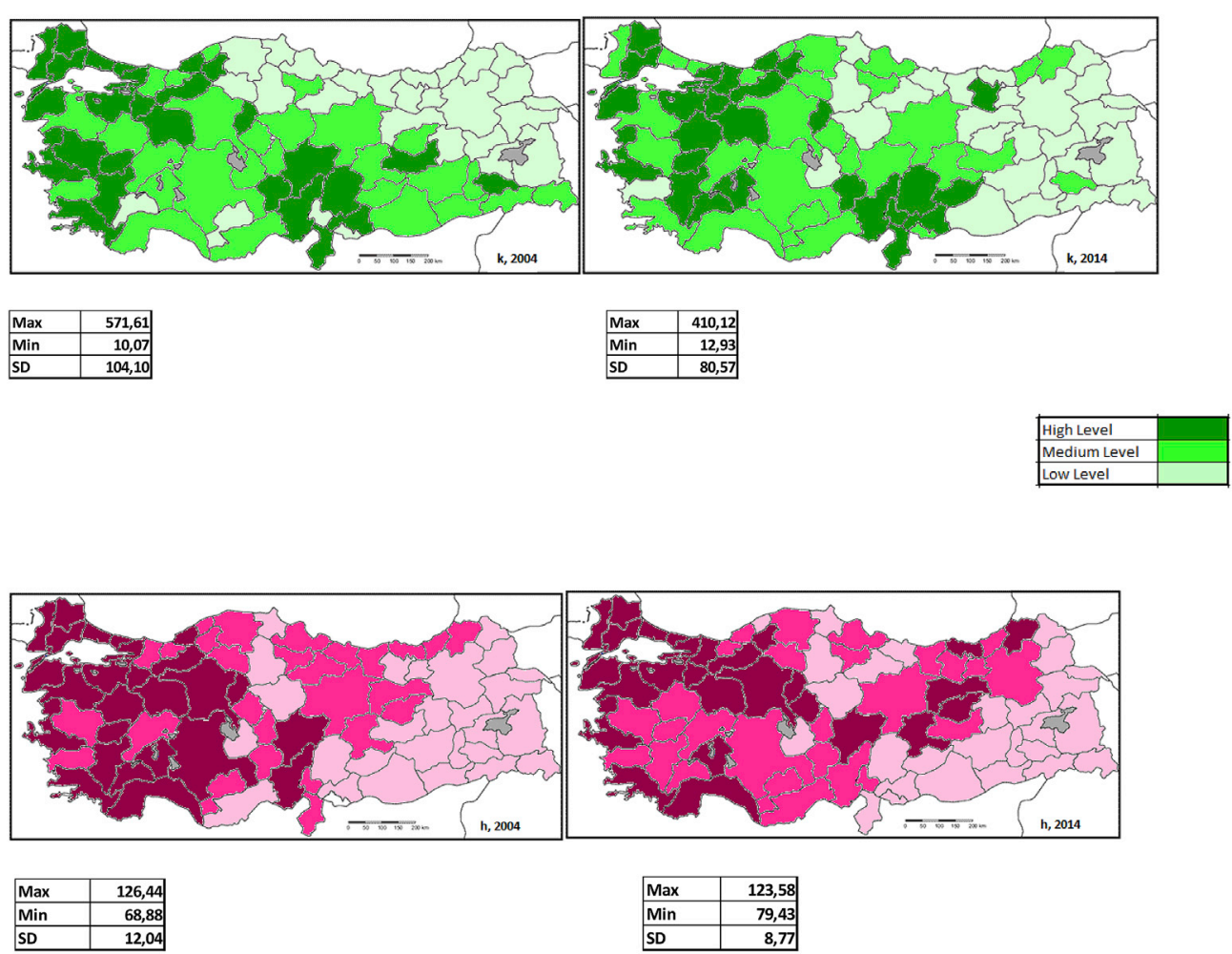

Fig. 5. Geographical Distribution of physical (k) and human capital stocks (h) (average province $=100$ ).

adopt the following Panel Unit Root test developed by Levin Lin Chiu (2002) which is commonly applied in the literature. In detail, the test relies on the ADF (Augmented Dickey Fuller) regression (Dickey \& Fuller, 1979) ${ }^{4}$ :

$$
\Delta x_{i, t}=\pi x_{i, t-1}+\sum_{j=1}^{\rho_{j}} \beta_{i, j} \Delta x_{i, t-j}+Y_{i, t}^{\prime} \delta+e_{i, t} \mathrm{i}=1, \ldots, 81 \text { provinces } \quad \mathrm{t}=2004, \ldots 2014 \text { years }
$$

where $\mathrm{x}$ is a panel variable. The coefficient of $\pi$ is critically important. The null and alternative hypotheses are stated as follows;

$$
\begin{aligned}
& \text { HO: } \pi_{1}=\pi_{2}=\pi_{N-1}=0 \\
& \text { HO: } \pi_{1} \neq \pi_{2} \neq \neq \pi_{N-1}<0
\end{aligned}
$$

If the null hypothesis is correct, it means that there exists a unit root and non-stationary series. If, however, alternative hypothesis is correct, stationary series are evident.

However, Levin, Lin and Ciu (2002) test is subjected to many criticisms. For instance, Madala and Wu (1999) emphasizes the point that the null hypothesis makes sense such that the assumption of none of the economies converging to a steady state might be relevant. However, alternative hypothesis is too strong. It is unlikely all economies converge at the same rate. Moreover, Levin, Lin, Chu (2002) is criticized since it ignores cross regional heterogeneity and dependence in unit root process. In contrast, it assumes a common and cross-regionally constant parameter of unit root. Im, Pesaran, and Shin (2003) provide a solution that assumes regional specific unit root process together with taking into account cross sectional dependence (see also Bai \& Ng, 2010; Pesaran, 2007).

We apply both Levin, Lin, and James Chu (2002) and Im et al. (2003) for the sake of cross validation.

In Table 5, the results of unit root analyses are provided. Since the time span is short, we set the time lag as 1 year in order for not losing much degrees of freedom. Our variables are expressed in levels and in relative form where cross regional average $=100$.

According to results, it is notable that in all variables we observe a negative and significant $\pi$ parameter. Both Levin, Lin, Chiu (2002)

\footnotetext{
${ }^{4}$ The panel unit root test equation and other related issues are mainly obtained from Eviews 6 and 10 program's user guide. Econometric analyses are performed in Eviews 10 and Eviews 8.
} 


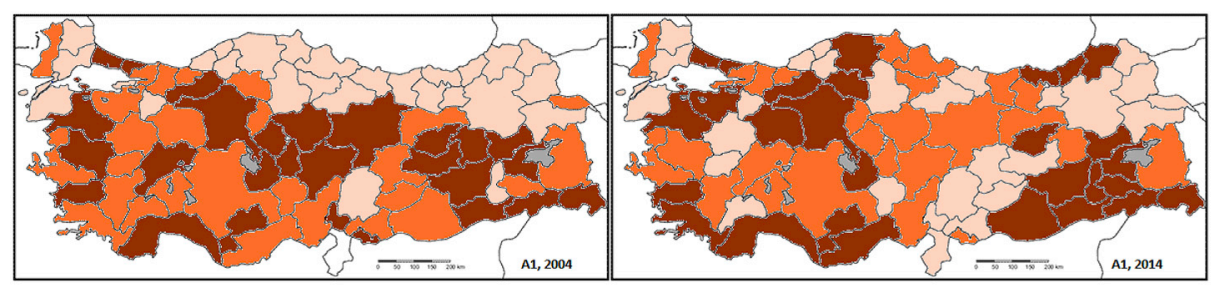

\begin{tabular}{|l|r|}
\hline Max & 208,27 \\
\hline Min & 43,30 \\
\hline SD & 37,51 \\
\hline
\end{tabular}

\begin{tabular}{|l|r|}
\hline Max & 219,56 \\
\hline Min & 49,32 \\
\hline SD & 29,10 \\
\hline
\end{tabular}

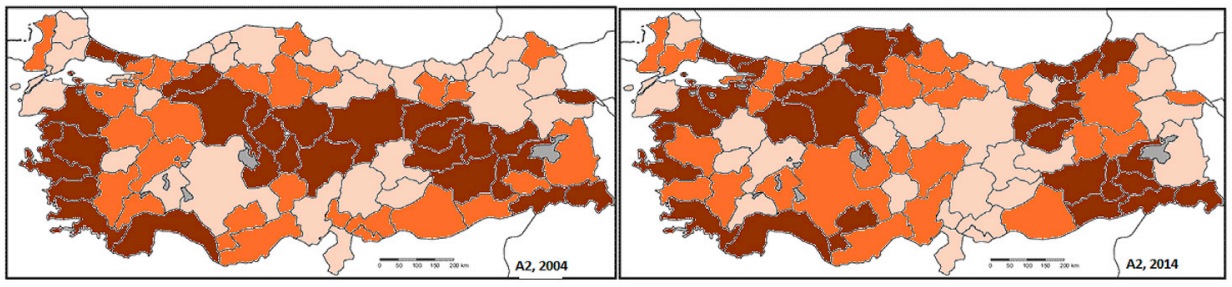

\begin{tabular}{|l|r|}
\hline Max & 198,98 \\
\hline Min & 37,02 \\
\hline SD & 30,94 \\
\hline
\end{tabular}

\begin{tabular}{|l|r|}
\hline Max & 193,51 \\
\hline Min & 59,03 \\
\hline SD & 22,33 \\
\hline
\end{tabular}

Fig. 6. Geographical Distribution of TFP Scores, average $=100$.

Table 3

Cross regional income inequality variance decomposition.

\begin{tabular}{|c|c|c|c|c|c|c|c|c|}
\hline \multirow[t]{2}{*}{ Years } & \multicolumn{4}{|c|}{ Variable $\alpha$ used } & \multicolumn{4}{|c|}{ Constant $\alpha$ used } \\
\hline & $\operatorname{var}\left(\log y_{i, t}\right)$ & $\operatorname{var}\left(\log y f_{i, t}\right)$ & $\operatorname{var}\left(\log A_{i, t}\right)$ & $2 x \operatorname{cov}(A, y f)$ & $\operatorname{var}\left(\log y_{i, t}\right)$ & $\operatorname{var}\left(\log y f_{i, t}\right)$ & $\operatorname{var}\left(\log A_{i, t}\right)$ & $2 x \operatorname{cov}(A, y f)$ \\
\hline 2004 & $100 \%$ & $63 \%$ & $71 \%$ & $-34 \%$ & $100 \%$ & $67 \%$ & $48 \%$ & $-15 \%$ \\
\hline 2005 & $100 \%$ & $69 \%$ & $73 \%$ & $-42 \%$ & $100 \%$ & $73 \%$ & $47 \%$ & $-20 \%$ \\
\hline 2006 & $100 \%$ & $72 \%$ & $67 \%$ & $-39 \%$ & $100 \%$ & $78 \%$ & $44 \%$ & $-21 \%$ \\
\hline 2007 & $100 \%$ & $77 \%$ & $68 \%$ & $-46 \%$ & $100 \%$ & $80 \%$ & $43 \%$ & $-24 \%$ \\
\hline 2008 & $100 \%$ & $76 \%$ & $63 \%$ & $-39 \%$ & $100 \%$ & $80 \%$ & $41 \%$ & $-21 \%$ \\
\hline 2009 & $100 \%$ & $78 \%$ & $64 \%$ & $-42 \%$ & $100 \%$ & $79 \%$ & $44 \%$ & $-23 \%$ \\
\hline 2010 & $100 \%$ & $110 \%$ & $65 \%$ & $-76 \%$ & $100 \%$ & $101 \%$ & $44 \%$ & $-45 \%$ \\
\hline 2011 & $100 \%$ & $94 \%$ & $67 \%$ & $-61 \%$ & $100 \%$ & $86 \%$ & $45 \%$ & $-31 \%$ \\
\hline 2012 & $100 \%$ & $96 \%$ & $72 \%$ & $-68 \%$ & $100 \%$ & $92 \%$ & $51 \%$ & $-43 \%$ \\
\hline 2013 & $100 \%$ & $92 \%$ & $69 \%$ & $-61 \%$ & $100 \%$ & $91 \%$ & $45 \%$ & $-36 \%$ \\
\hline 2014 & $100 \%$ & $91 \%$ & $69 \%$ & $-60 \%$ & $100 \%$ & $84 \%$ & $43 \%$ & $-27 \%$ \\
\hline
\end{tabular}

Note: All variables are used in relative sense, average province $=100$.

and Im, Pesaran, Shin (2007) test confirms stationary evolution of variables.

The interpretation of the results requires a special attention. The unit root analyses have been implemented only for the technical purposes to ensure stationary. Since the data is in relative form, the interpretation of regions' convergence to a steady state should be interpreted with a great caution. That's why, we pursue unit root analyses to understand only the stationarity property and to be able to use the levels of variables safely in the rest of the paper (i.e. Panel VAR analyses).

To be able to pursue a decomposition analysis, we follow an approach similar to what is applied in Klenow and Rodriquez-Clare (1997); Scott et al. (2006). The mathematical decomposition that they adopted:

$$
\operatorname{var}\left(d_{-} y_{i, t}\right)=\operatorname{var}\left(d_{-} y f_{i, t}\right)+\operatorname{var}\left(d_{-} A_{i, t}\right)+2 x \operatorname{cov}\left(d_{-} A_{i, t}, d_{-} y f_{i, t}\right)
$$

where all variables are expressed in terms of growth rates of relative (cross sectionally de-meaned) variables. Specifically, for instance, $d_{-} y_{i, t}=\log y_{i, t}-\log y_{i, t-1}$ represents the annual growth rates in relative income of province $i$ at year $t$. The full and reduced form of the decomposition results are presented in Tables 6 and 7. 
Table 4

Reduced form Cross Regional Income Inequality Variance Decomposition.

\begin{tabular}{|c|c|c|c|c|}
\hline \multirow[t]{2}{*}{ Years } & \multicolumn{2}{|c|}{ Varying Alpha } & \multicolumn{2}{|c|}{ Constant Alpha } \\
\hline & C & $1-C$ & C & $1-C$ \\
\hline 2004 & $47 \%$ & $53 \%$ & $59 \%$ & $41 \%$ \\
\hline 2005 & $49 \%$ & $51 \%$ & $61 \%$ & $39 \%$ \\
\hline 2006 & $52 \%$ & $48 \%$ & $64 \%$ & $36 \%$ \\
\hline 2007 & $53 \%$ & $47 \%$ & $65 \%$ & $35 \%$ \\
\hline 2008 & $54 \%$ & $46 \%$ & $66 \%$ & $34 \%$ \\
\hline 2009 & $55 \%$ & $45 \%$ & $64 \%$ & $36 \%$ \\
\hline 2010 & $63 \%$ & $37 \%$ & $70 \%$ & $30 \%$ \\
\hline 2011 & $58 \%$ & $42 \%$ & $66 \%$ & $34 \%$ \\
\hline 2012 & $57 \%$ & $43 \%$ & $64 \%$ & $36 \%$ \\
\hline 2013 & $57 \%$ & $43 \%$ & $67 \%$ & $33 \%$ \\
\hline 2014 & $57 \%$ & $43 \%$ & $66 \%$ & $34 \%$ \\
\hline Mean & $55 \%$ & $45 \%$ & $65 \%$ & $35 \%$ \\
\hline
\end{tabular}

Table 5

Levin Lin Chiu panel unit root convergence tests.

\begin{tabular}{lll}
\hline Variable & Levin, Lin, Ciu Test Statistic & Im, Pesaran, Shin CD Test Statistic \\
\hline$y$ & $-5,59^{* * * * *}$ & $-5,85^{* * * *}$ \\
$k$ & $-6,88^{* * * *}$ & $-6,65^{* * * *}$ \\
$h$ & $-1,21^{* *}$ & $-6,21^{* * * *}$ \\
$A 1$ & $-5,48^{* * * *}$ & $-5,68^{* * * *}$ \\
$A 2$ & $-5,36^{* * * *}$ & $-5,78^{* * * *}$ \\
\hline$* * * *$ &
\end{tabular}

$$
C_{-} d_{i, t}=\frac{\operatorname{var}\left(\mathrm{d}_{-} y f_{i, t}\right)}{\operatorname{var}\left(\mathrm{d}_{-} y f_{i, t}\right)+\operatorname{var}\left(\mathrm{d}_{-} A_{i, t}\right)}
$$

At a glance, it is observed that the main contributor to the income equalization process is the narrowing TFP differentials, whereas reduction in factor endowment disparities has rather a limited role.

In detail, initially, differences in TFP account for about $66-70 \%$ of the changes in relative income, while factor endowment disparities account for about $40-41 \%$. In the end year, the former accounts for $59-60 \%$ where the later accounts for $40-41 \%$. On average, the role played by TFP differences is roughly 61-62\%, whereas the role played by factor endowment disparities is about 38-39\%.

To understand the relative role played by variables in the evolution of income inequalities, We apply a Generalized Impulse Response functions. Thus, the following longitudinal-VAR model is designed:

$$
\begin{aligned}
& z_{t}=c+\sum_{j=1}^{J} A_{j} z_{t-j}+\mu_{t} \\
& z_{t}=\left\{y_{i, t}, k_{i, t}, A_{i, t}, h_{i, t}\right\}
\end{aligned}
$$

where $\mathrm{z}$ represents the set of endogenous variables to be used in the VAR analysis. All the variables are in level and relative form. We compute the Generalized Impulse Response Functions (IRF) to assess the response of relative income to relative capital endowment and technology shocks. We understand in this way the relative importance of the production factors and technology.

With regard to specific choice of IRF computation, conventional Impulse-Response or Variance Decomposition methods have an important drawback: the different Cholesky orders of variables give different IRF and variance decomposition results. Hence, to ensure the robustness of our results, we adopt Generalized Impulses as stated by Pesaran and Shin (1998). In this method, orthogonalized innovations do not depend on the VAR Cholesky ordering. Thus, it is a safer method against misleading results.

In VAR setting, all variables are interdependent with each other which is a fact providing advantage over other methods applied in this field. For instance, covariance term between factor endowments and TFP is found negative and significant which is generally assumed as exogenous to each other in the literature. The obtained results are summarized in Fig. 7. Both constant and region specific $\alpha$ values are used.

As an outcome, mostly technology (TFP) shocks (a1,a2) influence the relative income. The impact of capital stock (k,h) are rather limited. This result is consistent for both TFP types, regardless of whether alpha is constant or cross regionally variable. One may consequently argue that narrowing income differences are mostly driven by reduction of TFP differentials as it is mostly influential on the evolution of relative incomes. 
Table 6

Full Growth, decomposition.

\begin{tabular}{|c|c|c|c|c|c|c|c|c|}
\hline & $\begin{array}{l}\text { Variable } \alpha \text { used } \\
\operatorname{var}\left(\log y_{i, t}\right)\end{array}$ & $\operatorname{var}\left(\log y f_{i, t}\right)$ & $\operatorname{var}\left(\log A_{i, t}\right)$ & $2 x \operatorname{cov}(A, y f)$ & $\begin{array}{l}\text { Constant } \alpha \text { used } \\
\operatorname{var}\left(\log y_{i, t}\right)\end{array}$ & $\operatorname{var}\left(\log y f_{i, t}\right)$ & $\operatorname{var}\left(\log A_{i, t}\right)$ & $2 x \operatorname{cov}(A, y f)$ \\
\hline 2005 & $100 \%$ & $93 \%$ & $182 \%$ & $-175 \%$ & $100 \%$ & $64 \%$ & $146 \%$ & $-110 \%$ \\
\hline 2006 & $100 \%$ & $131 \%$ & $206 \%$ & $-237 \%$ & $100 \%$ & $98 \%$ & $157 \%$ & $-154 \%$ \\
\hline 2007 & $100 \%$ & $105 \%$ & $127 \%$ & $-132 \%$ & $100 \%$ & $69 \%$ & $102 \%$ & $-71 \%$ \\
\hline 2008 & $100 \%$ & $159 \%$ & $190 \%$ & $-249 \%$ & $100 \%$ & $110 \%$ & $131 \%$ & $-140 \%$ \\
\hline 2009 & $100 \%$ & $93 \%$ & $121 \%$ & $-114 \%$ & $100 \%$ & $82 \%$ & $99 \%$ & $-81 \%$ \\
\hline 2010 & $100 \%$ & $67 \%$ & $111 \%$ & $-78 \%$ & $100 \%$ & $41 \%$ & $85 \%$ & $-26 \%$ \\
\hline 2011 & $100 \%$ & $122 \%$ & $201 \%$ & $-223 \%$ & $100 \%$ & $128 \%$ & $210 \%$ & $-238 \%$ \\
\hline 2012 & $100 \%$ & $76 \%$ & $162 \%$ & $-139 \%$ & $100 \%$ & $108 \%$ & $200 \%$ & $-208 \%$ \\
\hline 2013 & $100 \%$ & $49 \%$ & $103 \%$ & $-52 \%$ & $100 \%$ & $47 \%$ & $90 \%$ & $-37 \%$ \\
\hline 2014 & $100 \%$ & $125 \%$ & $181 \%$ & $-206 \%$ & $100 \%$ & $99 \%$ & $150 \%$ & $-149 \%$ \\
\hline
\end{tabular}

Table 7

Reduced form Growth, decomposition.

\begin{tabular}{lllll}
\hline & Varying Alfa & & Constant Alfa & \\
& $C_{-} d$ & $1-C_{-} d$ & $C_{-} d$ & $3-C_{-} d$ \\
2005 & $34 \%$ & $66 \%$ & $38 \%$ & $70 \%$ \\
2006 & $39 \%$ & $61 \%$ & $40 \%$ & $62 \%$ \\
2007 & $45 \%$ & $55 \%$ & $46 \%$ & $60 \%$ \\
2008 & $45 \%$ & $55 \%$ & $45 \%$ & $54 \%$ \\
2009 & $43 \%$ & $57 \%$ & $33 \%$ & $55 \%$ \\
2010 & $38 \%$ & $62 \%$ & $38 \%$ & $67 \%$ \\
2011 & $38 \%$ & $62 \%$ & $35 \%$ & $62 \%$ \\
2012 & $32 \%$ & $68 \%$ & $34 \%$ & $65 \%$ \\
2013 & $32 \%$ & $68 \%$ & $40 \%$ & $66 \%$ \\
2014 & $41 \%$ & $59 \%$ & $38 \%$ & $60 \%$ \\
Mean & $39 \%$ & $61 \%$ & & $62 \%$ \\
\hline
\end{tabular}

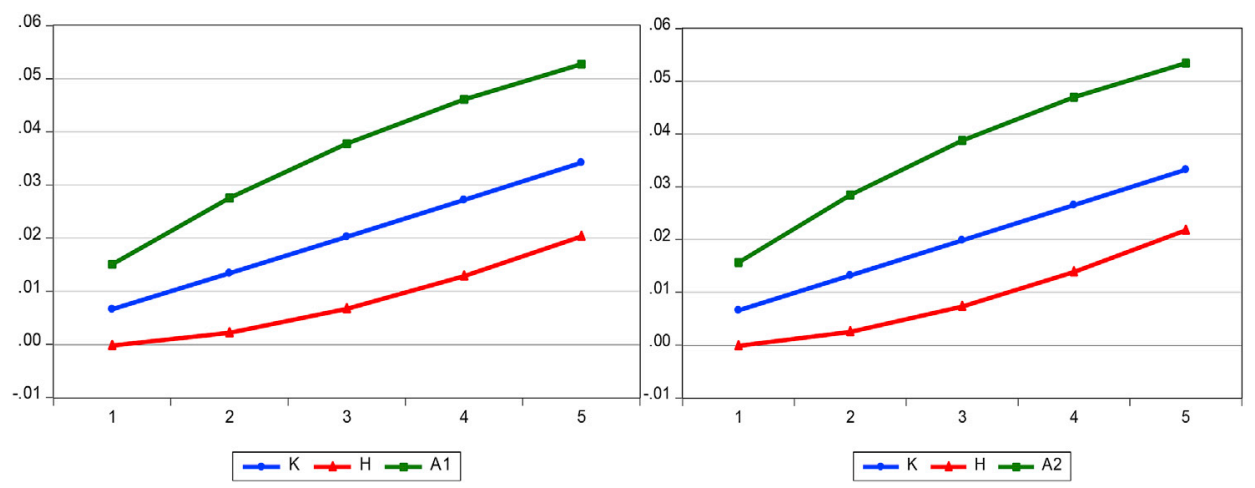

Fig. 7. Impulse response of variables to $\mathrm{Y}$, generalized impulse-responses.

\section{Conclusions}

In this study, we reached some quite important results about the reasons lying behind the observed provincial disparities. Unlike past literature, we adopted an empirical framework that investigated both the level and change in regional inequality, which produced different results.

Our results can be summarized in two groups. First, for the sources of the level of income inequality, the main contributor is the disparity in regional factor endowments, whereas TFP differentials are relatively less influential. Second, as for the sources behind the decline in disparities, the main driver is the narrowing of TFP differences. The results are shown to be robust across inferential, mathematical and explorative methods.

The obtained results have important policy implications. One the one hand, gross capital formation should be stimulated in backward regions. The investment opportunities, subsidies, tax exemptions, rental aid, and export subsidies to entrepreneurs should be directed to the lagging regions. Thus, speeding up the capital accumulation process in underdeveloped regions will help close the income gap between developed areas. 
On the other hand, the observed convergence process is found to be mainly driven by equalization of TFP levels. Hence, the productivity gap should also be closed. However, this is a harder task compared to the promotion of capital accumulation as it requires longterm perspectives and policies, such as enrichment of technology investments, infrastructure, RD, innovative activities, etc.

Overall, the main lesson that arises from our analysis is that both factors are almost equally important. One contributes more to the inequality levels while the other contributes to the decrease in regional inequality.

\section{Conflict of interest decleration}

I confirm that there are no conflicts of interest associated with my manuscript (Asymmetries in Regional Development: Does TFP or Capital Accumulation Matter for Spatial Inequalities?) and there has been no financial support for this work that could have influenced its outcome.

\section{Appendix A. Supplementary data}

Supplementary data to this article can be found online at https://doi.org/10.1016/j.jeca.2019.e00119.

\section{References}

Armstrong, H. W. (1995). Convergence among regions of the European Union, 1950-1990. Papers in Regional Science, 74(2), 143-152.

Bai, J., \& Ng, S. (2010). Panel unit root tests with cross-section dependence: A further investigation. Econometric Theory, $26,1088-1114$.

Barro, R. J., \& Sala-i-Martin, X. (1992). Convergence. Journal of Political Economy, 100(2), 223-251.

Beugelsdijk, S., Klasing, M., \& Milionis, P. (2018). Regional economic development in europe: The role of total factor productivity. Regional Studies, 52(4), 461-476. Bosworth, D. L. (1979). Capital stock, capital services and the use of fuel consumption proxies. In K. Patterson, \& K. Schott (Eds.), The measurement of capital. Macmillan. Brock, G., \& German-Soto, V. (2013). Regional industrial growth in Mexico: Do human capitaland infrastructure matter? Journal of Policy Modeling, 35, 228-242. Burnside, A. C., Eichenbaum, M., \& Rebelo, S. T. (1996). Sectoral solow residuals. European Economic Review, 40(3-5), 861-869.

Byrne, J., Fazio, G., \& Piacentino, D. (2009). Total factor productivity convergence among Italian regions: Some evidence from panel unit root tests. Regional Studies, 43(1), 63-76.

Caselli, F. (2005). Accounting for cross-country income differences. In P. Aghion, \& S. N. Durlauf (Eds.), Vol. 1a. Handbook of economic growth (pp. 679-741). Amsterdam: Elsevier.

Comin, D., \& Gertler, M. (2006). Medium-term business cycles. The American Economic Review, 96(3), 523-551.

De La Fuente, \& Angel. (2002). On the sources of convergence: A close look at the Spanish regions. European Economic Review, 46, $569-599$.

Dettori, B., Marrocu, E., \& Paci, R. (2012). Total factor productivity, intangible assets and spatial dependence in the european regions. Regional Studies, 46(10), $1401-1416$.

Dickey, D. A., \& Fuller, W. A. (1979). Distribution of the estimators for autoregressive time series with a unit root. Journal of the American Statistical Association, 74(366), 427-431.

Duran, H. E. (2014). Short-run dynamics of income disparities and regional cycle synchronization in the U.S. Growth And Change, 45(2), 292-332.

Duran, H. E. (2015). Non-linear regional income divergence and policies: Turkey case. Regional Science Inquiry, O(2), $107-114$.

Durlauf Steven, N., Kourtellos, A., \& Tan, C. M. (2008). Are any growth theories. Robust" The Economic Journal, 118(527), 329-346.

Elveren, A. Y. (2010). Wage inequality in Turkey: Decomposition by statistical regions, 1980-2001. Review of Urban \& Regional Development Studies, 22(1), 55-72.

Ertur, C., Le Gallo, J., \& Baumont, C. (2006). The european regional convergence process, 1980-2995: Do spatial regimes and spatial dependence matter? International Regional Science Review, 29(1), 3-34.

Fan, C. C., \& Casetti, E. (1994). "The spatial and temporal dynamics of US regional income inequality, 1950-1989. The Annals of Regional Science, 28, 177-196.

Feenstra, R. C., Robert Inklaar, \& Timmer, M. P. (2015). The next generation of the Penn World table. The American Economic Review, $105(10), 3150-3182$.

Gezici, F., \& Hewings Geoffrey, J. D. (2007). Spatial analysis of regional inequalities in Turkey. European Planning Studies, 15(3), 383-403.

Gömleksiz, M., Sahbaz, A., \& Mercan, B. (2017). Regional economic convergence in Turkey: Does the government really matter for? Economies, 5(27), 1-16.

Hall, R. E., \& Jones, C. I. (1999). Why do some countries produce so much more output per worker than others? Quarterly Journal of Economics, 114(1), 83-11.

Hsieh, C.-T., \& Pete Klenow, P. J. (2010). Development accounting. American Economic Journal: Macroeconomics, 2(1), $207-223$.

Im, K. S., Pesaran, M. H., \& Shin, S. Y. (2003). Testing for unit roots in heterogeneous panels. Journal of Econometrics, 115(1), 53-74.

Karahasan, B. C. (2015a). Dynamics of regional new firm formation in Turkey. Review of Urban \& Regional Development Studies, $27(1)$, 18-39.

Karahasan, B. C. (2015b). "Regional inequalities in Turkey: Post 2001 era". Marmara üniversitesi 37 no 1, I.I.B. Dergisi, $27(1), 125-147$.

Karahasan, B. C., Dogruel, F., \& Suut Dogruel, A. (2016). Can market potential explain regional disparities in developing countries? Evidence from Turkey. The Developing Economies, 54(2), 162-197.

Kirdar, M. G., \& Saracoglu, S. (2008). Migration and regional convergence: An empirical investigation for Turkey. Papers in Regional Science, 87(4), 545-566.

Klenow, Peter, \& Rodríguez-Clare, Andrés (1997). The neoclassical revival in growth economics: Has it gone too far?. In , NBER Macroeconomics Annual 1997: 12. NBER Chapters (pp. 73-114). National Bureau of Economic Research, Inc.

Levin, A., Lin, C.-fu, \& James Chu, C.-S. (2002). Unit root tests in panel data: Asymptotic and finite-sample properties. Journal of Econometrics, $108(1), 1-24$.

Lopez-Bazo, E., Vaya, E., Mora, A. J., \& Surinach, J. (1999). Regional economic dynamics and convergence in the European Union. The Annals of Regional Science, 33, 343-370.

Madala, G. S., \& Wu, S. (1999). A comparative study of unit root tests with panel data and new simple test. Oxford Bulletin of Economics \& Statistics, 61, 631-652.

Mincer, J. (1984). Human capital and economic growth. Economics of Education Review, 3(3), 195-205.

Oktay, E., \& Gozgor, G. (2013). Trade and regional development in a developing country: The case of Turkey. Review of Urban \& Regional Development Studies, 25(3), 201-212.

Pesaran, M. H. (2007). A simple panel unit root test in the presence of cross-section dependence. Journal of Applied Econometrics, 22(2), 265-312.

Rey, S. J., \& Montouri Brett, D. (1999). US regional income convergence: A spatial econometric perspective. Regional Studies, 33(2), $143-156$.

Scott, B. L., Dwyer, G. P., \& Tamura, R. (2006). How important are capital and total factor productivity for Economic Growth? Economic Inquiry, 44(1), 23-49.

Solow, R. M. (1956). A contribution to the theory of economic growth. Quarterly Journal of Economics, 70(1), 65-94.

Swan, T. W. (1956). Economic growth and capital accumulation. The Economic Record, 32, 334-336.

Taylor, J. (1967). A surrogate for regional estimates of capital stock. Oxford Bulletin of Economics \& Statistics, $29(3), 289-299$.

www.tuik.gov.tr. 